ISSN 2469-0783

Editorial MenteClara

Fundación MenteClara

info@menteclara.org

\section{Revista Científica Arbitrada de la \\ Fundación MenteClara}

Revista Cientifica Arbitrada de la Fundación MenteClara

Artículos atravesados por (o cuestionando) la idea del sujeto -y su género- como una construcción psicobiológica de la cultura. Articles driven by (or questioning) the idea of the subject -and their gender- as a cultural psychobiological construction

Vol. 2 (1), 2017

ISSN 2469-0783

https://datahub.io/dataset/2017-2-1-e25

\title{
DICEN LAS CRÓNICAS QUE UN MONJE BUDISTA... a
}

\section{CHRONICLES SAY THAT A BUDDHIST MONK...}

Anamaria Ashwell aashwell@gmail.com

Benemérita Universidad Autónoma de Puebla. Instituto de Ciencias

Sociales y Humanidades, México.

Citación: Ashwell, A. M. (2017). "Dicen las crónicas que un monje budista...". Revista Científica Arbitrada de la Fundación MenteClara, 2(1), 76-112.

DOI: $10.32351 /$ rca.v2.1.27

Copyright: (C) 2017 RCAFMC. This open access article distributed under the terms of the Creative Commons Attribution-Non Commercial (by-cn) Spain 3.0. Received: 28/04/2017. Accepted: 29/04/2017 Published online: 30/04/2017

Conflicto de intereses: Ninguno que declarar.

\section{Resumen}

Crónica del viaje que realizó un monje budista llamado Hwui Shan que arribó a la tierra del Fusang, probablemente Mesoamérica, entre 499 d. C. y 548 d. C. y que retornó a China con noventa años de edad. En el año 629 d. C. un grupo de historiadores oficiales de la corte de la dinastía Liang documentó el extraordinario viaje de los cinco monjes y sus descripciones de la tierra del Fusang. Extractos del Liáng Shū fueron también incluidos por Ma Taulin o Ma Twan-lin en su enciclopedia histórica llamada Wen-hsien t'ung-K'ao "Investigaciones de antiguallas" publicada por el emperador mongol Jintsung alrededor de 1321. Este artículo nos documenta además la resistencia oficial mexicana para abrirse a la posibilidad de iniciar investigaciones ciertas ya que las ofrecidas hieren cierto orgullo nacionalista de los antropólogos mexicanos e impiden profundizar mediante una investigación

a Nota del editor: Este artículo es una reimpresión del original cedido a nuestra editorial por la Revista Elementos de la Universidad de Puebla. La publicación original (Ashwel Ana María. "Dicen las crónicas de un monje budista..." Revista Elementos, Num. 70 Vol. 15 (2008) Pag 3-17) puede verse en http://www.elementos.buap.mx/num70/htm/3.htm Agradecemos la generosidad de la autora y del director editorial Enrique Soto 
multidisciplinaria en la posibilidad de alguna interacción cultural asiática en Mesoamérica

\begin{abstract}
Chronicle of the journey made by a Buddhist monk named Hwui Shan who arrived to Fusang, probably Mesoamerica, between AD 499 and AD 548 and returned to China when he was 90 years old. In AD 629, a group of official historians from the court of the Liang dynasty documented the extraordinary journey of five monks and their descriptions of the Fusang. Ma Taulin or Ma Twan-lin's historical encyclopedia called Wen-hsien t'ung-K'ao ("Investigations of Antiques"), published by Mongol emperor Jintsung around 1321, also included excerpts from the Book of Liang or Liáng Shū. This article also documents the Mexican official reluctance to be open to the possibility of initiating true research on this topic since the existing one hurts some kind of nationalistic pride of Mexican anthropologists and prevents to dig into, through multidisciplinary research, the possibility of some Asian cultural interaction in Mesoamerica.
\end{abstract}

\title{
Palabras Claves/ Keywords
}

Fusang; Mesoamérica; Asia; exploradores chinos; monjes budistas; chinos en América precolombina; vikingos en america precolombina; Chinese explorers; Buddhist monks; Chinese in pre-Columbian America; Vikings in pre-Columbian America 


\section{Dicen las crónicas que un monje budista... ${ }^{1}$}

Hwui Shan² nació en Afganistán. Fue un "sha-man", dicen las crónicas, o un monje budista mendicante que arribó a China cerca del año 450 d.C.

$\mathrm{Su}$ extraordinario viaje, en compañia de cuatro monjes, se inició cuando ellos navegaron el gran mar, desde China hacia el Este -entre 499 d.C. y 548 d.C.- hasta arribar a la tierra del Fusang.

Hwui Shan y los cuatro monjes partieron de China durante la dinastía Sung establecida en Nanking (420-479 d.C.); él retornó a China con noventa años de edad, pero no existen registros o noticias sobre la suerte que corrieron sus acompañantes.

Su arribo a China quedó registrado en los archivos de la dinastía Chiłi o Tsi (479-502 d.C.).

Los registros de la dinastía Chi'i ${ }^{3}$ se perdieron, sin embargo el viaje de Hwui Shan quedó reproducido en los documentos de la dinastía Liang (502-557 d.C.); éstos también se extraviaron, pero por fortuna -en el año 629 d.C.- un grupo de historiadores oficiales de la corte, entre los cuales estaba Yao Silian (557637 d.C.) ${ }^{4}$ documentó el extraordinario viaje de los cinco monjes y sus descripciones de la tierra del Fusang.

Extractos del Liang Shu fueron también incluidos por Ma Taulin o Ma Twan-lin en su enciclopedia histórica llamada Wen-hsien t’ung-K’ao (Investigaciones de antiguallas) publicada por el emperador mongol Jintsung alrededor de 1321.5

De esta enciclopedia antigua tomó el relato de Hwui Shan el sinólogo francés De Guignes y lo publicó en 1761; posteriormente el alemán Karl Friedrich Neumann lo tradujo al alemán alrededor de 1840.6 
El relato del transoceánico viaje de Hwui Shan y sus cuatro acompañantes ocurrió en tiempos del Imperio Romano en Europa y cuando Mesoamérica se distinguía por el predominio de las grandes urbes o centros ceremoniales: Teotihuacan, Cholula, Cuicuilco, en el altiplano; Palenque, Tikal, Izapa, Dzibichaltún, Kaminaljuyú, Abaj Takalik o Piedra Parada, en la región mayaquiché; Monte Albán, en el valle de Oaxaca, así como Chupícuaro, en Michoacán, entre muchos otros.

A este prolongado periodo de la preeminencia de las ciudades ceremoniales, los arqueólogos le dieron el nombre de "horizonte clásico".

En el siglo $\mathrm{V}$ del viaje de los cinco monjes budistas a la tierra del Fusang, como lo argumenta magistralmente C. Duverger, el territorio mesoamericano se organizaba en torno a una rivalidad entre sus zonas nahua y maya que duraría varios siglos. ${ }^{7}$

Por largo tiempo varios investigadores de cartografias y de las primeras navegaciones transoceánicas desde Asia al Nuevo Mundo, especialmente en el siglo XIX y comienzos del XX, se preguntaron por la localización geográfica de las tierras y culturas del Fusang que Hwui Shan describe en su relato. La posibilidad de que el monje y sus acompañantes hayan arribado al continente americano navegando hacia el Este desde China el viaje de Hwui Shan ocurrió quinientos años antes que los de Leif Ericson ${ }^{\mathrm{b}}$ y mil años antes de la llegada de Colón al continente americano-

\section{b Nota del Editor}

Explorador vikingo considerado como uno de los primeros europeos que llegó a América del Norte. Nacido en Islandia, llegó en el año 1000 a un lugar de América que llamó Vinland posiblemente en en la actual Canadá (1)

(1) Magnusson, Magnus y Hermann Pálsson The Vinland sagas: the Norse discovery of America: Grændlendinga saga and Eirik's saga (1965), Middlesex, England: Penguin Books Ltd., c. 1965, FHL book 949.12 H7vm., (P. E.) pp. 84-85. 
naturalmente dio lugar a muchas conjeturas. Por ello importantes sinólogos, viajeros y naturalistas dieron la noticia del viaje de Hwui Shan y sus cuatro acompañantes; por ejemplo, Alexander von Humboldt lo describe como el Leif Ericson de China seguramente influenciado por sinólogos franceses como M. De Guignes quien, ya en 1761, aseguraba que Hwui Shan arribó si no a México por lo menos hasta California.

Fue, sin embargo, un sinólogo alemán llamado Karl Friedrich Neumann, alrededor de 1841, quien ofreció la propuesta más documentada y audaz: la maravillosa tierra de Fusang descrita por Hwui Shan podía ser, nada más ni nada menos, que México; es decir, las tierras de las culturas clásicas de Mesoamérica. ${ }^{8}$

\section{LA TRADUCCIÓN Y TRAICIÓN AL INGLÉS DEL RELATO DEL VIAJE DE HWUI SHAN}

Entra en escena Charles Godfrey Leland, en ese entonces un joven estudiante de Princeton que alrededor de 1847 asistía a la Universidad de Heidelberg y que conoció las teorias de Friedrich Neumann sobre el viaje del monje budista a México en el siglo $\mathrm{V}$.

Karl Friedrich Neumann (nació en 1798) era profesor de lenguas orientales y de historia en la Universidad de Munich. Este puesto le fue concedido sólo después de que se convirtió del judaísmo al protestantismo; y luego de un viaje a China donde residió dos años y adquirió a sus expensas, en Cantón, una biblioteca de diez mil volúmenes que a su regreso a Alemania donó al gobierno bávaro.

Fue autor de numerosos libros, como lo cuenta Leland, sobre el latín, francés e inglés. En 1841 Neumann publicó el relato original -con una traducción al alemán- del viaje de Hwui Shan tomado de "Investigaciones 
de antiguallas" de Ma Twan-lin de 1317, y adicionó sus propios comentarios y conjeturas.

Leland tradujo al inglés la versión del chino al alemán de Neumann del relato de viaje de Hwui Shan, según lo explicó él mismo: "Este pequeño trabajo lo he traducido al inglés bajo la supervisión del profesor Neumann". Sin embargo, existe con fecha de 1871 una carta dirigida a su hermano en Estados Unidos, a quien apresura a buscarle un editor, con esta acotación: "algunas palabras no las entiendo... pero tú puedes corregirlas fácilmente, y si no es así, déjalas pasar, no les des una excusa para no publicarlo, deja pasar las fallas y todo lo demás". La traducción de una traducción, del alemán al inglés, también cuenta con esta observación en la edición de Leland: "[...] desde que se escribieron los capitulos anteriores, su autor, mi viejo amigo y maestro, ha muerto [...]" refiriéndose a los capítulos iniciales que escribió Neumann para la edición de 1875 .

La primera traducción de Leland, entonces, de 1871 -y que salió publicada en la revista Knickerbocker de Nueva York en 1874- con todas las salvedades anotadas, será también la que él incorporó al libro editado en 1875 .

Esta edición contiene un prefacio con los antecedentes de la investigación sobre el relato de Hwui Shan, una carta de un experto navegante de los océanos, el coronel Barclay Kennon, y extensas argumentaciones sobre la probabilidad de que la tierra del Fusang fuera México o Perú. 9

Poco tiempo después de la difusión del libro de Leland -en la época en que la investigación arqueológica y de fuentes coloniales sobre Mesoamérica no existía como hoy-, naturalistas y navegantes, incluso 
literatos, retomaron y ampliaron los datos sobre la hipótesis de que el viaje de Hwui Shan en el siglo v hubiera sido a México.

Historiadores y académicos de la American Oriental Society, ${ }^{10}$ con la misma pobreza de fuentes, por su lado, descartaron esa posibilidad; algunos historiadores de antigüedades razonaron que la tierra del Fusang, "East of China", podría ubicarse en las inmediaciones de China y apuntaron hacia Corea y Japón.

El relato de Hwui Shan publicado por Neumann/Leland, sin embargo, llamaría la atención de una poderosa imaginación, la de Edward Payson Vining. Vining era gerente de embarques para la Union Pacific Railroad y gozaba de una muy mala reputación: contemporáneos suyos lo describen como un negociador ventajoso y sin escrúpulos. Pero su oscura personalidad en los negocios tenía un lado luminoso en su faceta de escritor: lo caracterizaba una curiosidad ilimitada, también una dedicación incansable para desarrollar y fundamentar las hipótesis más descabelladas, volviéndolas probables o posibles en sus libros. En 1881 escribió, por ejemplo, uno titulado “The Mystery of Hamlet” (E1 Misterio de Hamlet). Se trata de una larga e intrincada argumentación demostrando que Shakespeare sugirió que Hamlet fue una mujer que se disfrazó de hombre para asegurarse el trono danés. El hermano del asesino de Abraham Lincoln, el actor Edwin Booth, llevó a los escenarios esta propuesta y la película danesa de 1920, con la actriz Asta Nielsen, la llevó a la pantalla.

Setecientos cuarenta y seis caracteres o ideogramas chinos constituyen el total de la extensión del relato de Hwui Shan que Neumann/Leland tradujeron y que catapultó -no hay otra palabra- la imaginación de Payson Vining; porque Vining convirtió ese corto relato del monje budista en un libro de ochocientas páginas. 
Ed Parks -quien ha estudiado detalladamente An Inglorious Columbus, título que Payson Vining dio a su obra publicada en 1885concluye que es un tratado "fascinante", aunque también "casi ilegible". Vining incluyó en su libro una argumentación tan extensa como intrincada, llena de densas explicaciones gramaticales, historias minuciosas -por ejemplo, sobre el budismo-, e incluyó extensas reproducciones y citas de todos los argumentos que sinólogos y exploradores anteriores habian escrito sobre el monje y su viaje transoceánico en el siglo V. Además, incluyó en el libro la versión original -con caracteres chinos tomados de Ma Twan-lin- con ocho posibles traducciones, incluyendo una propia aunque Payson Vining no conoció el chino.

Un acto de locura literaria, sin lugar a dudas, que le permitió arribar a varias conclusiones fascinantes (derivadas algunas de complejísimos argumentos gramaticales); por ejemplo, que la deidad tolteca Quetzalcoatl no significa "serpiente emplumada" sino "visitante de honor" y que ése fue el mismísimo Hwui Shan en Mesoamérica. ${ }^{11}$

\section{LA TIERRA DEL FUSANG}

La argumentación más recurrida (y documentada) sobre la trayectoria que Hwui Shan pudo haber tomado hasta arribar a la tierra del Fusang -si ésta estuviera localizada en América y debido a la magra recuperación arqueológica de artefactos mesoamericanos en ese tiempo- sólo podía provenir de quienes habian navegado los océanos.

La investigación arqueológica y de fuentes coloniales sobre las culturas mesoamericanas, ya no diré de su primera época, estaban y están aún 
en desarrollo y discusión como para que pudieran servir de pruebas del arribo del monje en el siglo v a tierras mesoamericanas.

Si el árbol del Fusang en el relato del monje es una referencia al maguey o al nopal mexicano; si se distingue o no la figura del Buda en esculturas mesoamericanas; si son similares los "montículos" sagrados de la India, China y Mesoamérica o si el

[...] mito del nacimiento del terrible dios Azteca de la guerra contiene desteñidos elementos de la vieja religión hindú [... ya que...] Huitzilopotschli [sic] de México nació de la misma forma maravillosa que Schakia en la India: su madre vio flotando en el aire una bola de plumas brillantes que acomodó debajo de su pecho, quedando embarazada; y dio a luz a su terrible hijo que llegó al mundo sosteniendo una lanza en su mano derecha y un escudo en su izquierda mientras sobre su cabeza se desplegaba un penacho de plumas verdes $[\ldots]$

como escribió Neumann/Leland en 1875. Todo ello, y más, requiere de mayores imaginaciones y dedicaciones, de antropólogos y arqueólogos, quienes, además, han eludido o descartado puntualmente el tema de la posible relación entre Asia y Mesoamérica en sus investigaciones hasta hoy.

En el libro de Leland, quizás la opinión más documentada y por eso la más popular sobre la trayectoria que pudieron haber tomado los monjes en el siglo V, la ofrece una carta del coronel Barclay Kennon, cuya experiencia marítima es extensa: él fue el navegante en jefe de la expedición que Estados Unidos mandó para cartografiar el Pacífico norte entre 1853 y 1856. 
El marinero explica detalladamente que entre el continente asiático y el americano se encuentran las islas Aleutianas, que le permiten a cualquier navegante en una trayectoria marítima hacia el Este desde China mantenerse cerca de tierra firme. Y relata que él mismo realizó ese viaje, por esa ruta, calificándola de "placentera", resumiendo que "según le he descrito, y es resultado de la observación científica más rigurosa, es evidente que la travesía desde China a América puede realizarse sin perder de vista tierra firme por más de unas horas a la vez"; agregó además, una respuesta a una pregunta que le hace Leland:

[...] si yo puedo ofrecer pruebas o probabilidades de que durante este gran periodo de tiempo entre el siglo V y VII, cuando el mundo estaba tan abundantemente ocupado en llevar a cabo conversiones a diversas religiones [...] monjes budistas pudieron haber arribado a estas islas [...] si lo hicieron, seguramente no permanecieron allí (en estas islas) por mucho tiempo, sino que se hubieran apresurado a navegar hacia costas más hospitalarias en el continente americano. Porque literalmente no existen ni árboles en estas islas [...] algunos no son más que arbustos [...] con ramas no más largas que el brazo de un hombre [...] no dudo que en los tiempos más remotos, en todas las costas, los pescadores en barcos, canoas, incluso barquillas de cuero, guiados simplemente por las estrellas y las corrientes no dudaron en adentrarse mar adentro. Hoy en dia, los nativos de muchas islas en el Pacífico sur llevan a cabo exitosas travesias, sin siquiera un compás [... además] en el Pacífico norte existen corrientes maritimas, una llamada Kurosuvo ${ }^{12}$ o corriente japonesa, que pasa al sureste de la costa japonesa, se dirige al Este hasta arribar a California; de alli se desvía por la costa hasta México y América Central a una latitud aproximada de 10 grados $N$ hasta 
encontrarse con la corriente Humboldt o peruana [... y] finalmente completa su trayectoria [ nuevamente] en la costa de Japón [... ]

Las corrientes maritimas del Japón, conocidas por los navegantes en esos tiempos y recurridas por barcos hasta el presente, conforman una suerte de río dentro del océano Pacífico norte que transporta a embarcaciones, en dirección al Este, a velocidades que alcanzan entre setenta y cien millas diarias.

El relato de Hwui Shan describe que ellos navegaron al noreste de Japón hasta las tierras de Ta-han (la Península de Kamchatka en Siberia). De allí navegaron 20,000 li (aproximadamente 6,600 millas) al Este y al Sur hasta la maravillosa tierra del Fusang:

En el año del reinado Yung-yuen del emperador Tung Hwan-hau de la dinastía Tsi (499 d.C.) un sha-man de nombre Hwui-shin llegó a King-chau desde el reino de Fusang. Él contó lo siguiente: "Fusang se encuentra más de 20,000 li al Este del reino de Tahan, también al Este del reino Medio". ${ }^{13}$

Esta dirección y distancias navegables, incluso en el siglo V, son plausibles y consecuentemente son las "pruebas" más recurridas por escritores, artistas, aventureros o marinos que han mantenido abierta la discusión y la posibilidad de que aquellos monjes llegaran a México desembarcando en islas y tierra firme a lo largo de una trayectoria nórdica en el Océano Pacífico, desde China, por las islas Aleutianas hasta Alaska, y de ahí por la costa oeste americana hasta México, en el siglo V. ${ }^{14}$

El relato de Hwui Shan explica, además, que una vez que los monjes arribaron a la tierra del Fusang, permanecieron allí estudiando las 
costumbres locales y convirtiendo al budismo a los nativos, durante 40 años.

Los que insisten en que Fusang es México han trazado, asimismo, la ruta y calculado las distancias y ubican a Hwui Shan y los cuatro monjes desembarcando en el actual puerto de Acapulco.

Se recurre también a otro dato del relato de Hwui Shan para sustentar la idea que lo ubica en México: cuando cumplió noventa años Hwui Shan había retornado a China; era el año 499 d.C. y llevó consigo como regalo para el emperador Wu Tique trescientas libras de kin -traducida como "seda", aunque "tela bordada y multicolor" sería más exacto- producida de las fibras del árbol Fusang, y un espejo de vidrio volcánico, posiblemente de obsidiana.

A continuación ofrezco una traducción del relato de viaje de Hwui Shan, según la traducción de Leland (1847) del alemán al inglés, correspondiente al viaje en la tierra del Fusang, con las salvedades ya anotadas y la invitación a algún estudioso del chino antiguo que nos pudiera rendir en el futuro una traducción más fidedigna y directa del chino antiguo original al español:15

Durante el reinado de la dinastía Tsi, en el primer año del año llamado "Origen Eterno" (499 d.C.) llegó un monje budista de este reino, que tenia por nombre de clausura Hoei-schin, es decir, Compasión Universal, al presente distrito de Hukuang, y los circundantes, que narró que Fusang se encuentra aproximadamente a veinte mil millas chinas (li) en una dirección Este de Tahan y al Este del Reino Medio.

Muchos árboles Fusang crecen alli, cuyas hojas se asemejan al árbol tung o Dryanda cordifolia; los brotes por el contrario se parecen 
al árbol del bambú y sirven de alimento a los nativos de esas tierras. La fruta tiene forma de una pera pero es de color rojo. De la corteza preparan telas que utilizan para sus ropas y también cosas ornamentadas (de seda fina o brocados). Las casas están construidas con vigas de madera, no se conocen viviendas fortificadas ni lugares amurallados.

Ellos tienen caracteres y escritura en estas tierras y preparan papel de la corteza del Fusang. Los nativos no tienen armas y no hacen la guerra; pero al organizar su reino tienen una prisión en el norte $y$ otra en el sur. Trasgresores menores son alojados en las prisiones del sur pero aquellos grandes ofensores se confinan en el norte; aquellos dispuestos a recibir condonaciones pueden ser alojados en las prisiones del sur, y aquellos que no en las del norte. Aquellos hombres y mujeres confinados de por vida se les permite el matrimonio. Los hijos que resultan de estos matrimonios a la edad de ocho años son vendidos como esclavos, asi también las niñas, pero hasta que cumplen nueve años.

Si un hombre connotado es acusado de un crimen se reúne una asamblea; debe ser en un lugar excavado. Alli le arrojan ceniza y lo despiden. Si el culpable es de las clases inferiores, se le castiga únicamente a él; pero cuando tiene rango superior el castigo alcanza a sus hijos y nietos. Con aquellos del más alto rango el castigo se extiende hasta la séptima generación.

El nombre del rey se pronuncia yueh-ki. Los nobles de primer rango se llaman tui-lu; los de segundo, pequeño tui-lu; los de tercero, no-cha-sha. ${ }^{16}$ Cuando el principe avanza le acompañan cornetas $y$ trompetas. Los colores de su vestimenta cambian con cada año; en 
los primeros dos del ciclo de diez años son azules; en los siguientes dos, rojo; $y$ en los últimos dos, negro.

Los cuernos de los bueyes son tan grandes que algunos pueden contener hasta 350 litros. ${ }^{17}$ Los utilizan para guardar todo tipo de cosas.

Caballos, bueyes y venados son amarrados a las carretas. Los venados se utilizan como ganado igual que en el Reino Medio y de la leche se produce mantequilla.

Las peras rojas del árbol Fusang se mantienen bien todo el año. También tienen manzanas y cañas (o carrizo). De estos tejen tapetes. No se encuentra hierro en estas tierras; pero si existe el cobre, oro y plata que no son apreciados y no sirven para intercambio en el mercado.

El matrimonio se decide de esta manera: el pretendiente construye una choza delante de la puerta de la casa donde habita la pretendida y riega y lava el suelo cada mañana y noche. Cuando ha pasado un año, si la pretendida no se inclina por un matrimonio, él se aleja; si ella accede se consuma. Cuando los padres mueren se ayuna siete dias. Por la muerte del abuelo paterno o materno se lamenta cinco dias; por la muerte de hermanos mayores o menores, tios o tías, tres dias. Posteriormente se sientan en frente de una imagen del fantasma, absortos en rezos, pero no utilizan vestuario específico para velar. Cuando muere el rey, el hijo que lo reemplaza no se ocupa de asuntos del Estado por tres años.

En tiempos anteriores estos pueblos no vivieron bajo la ley del Buda. Pero sucedió que en el segundo año llamado "Gran Luz" del Canto (458 d.C.), cinco monjes mendicantes del reino de Kipin 
llegaron a sus tierras y extendieron sobre ellas la religión del Buda y sus sagradas escrituras e imágenes. Ellos les instruyeron sobre los principios de la vida monástica y así cambiaron sus creencias. ${ }^{18}$

\section{México entre oriente y occidente}

Este es, en realidad, el título ${ }^{19}$ que Paul Kirchhoff le dio a un ensayo preparatorio e inédito que anuncia un listado detallado de los sistemas religiosos, basados en doce dioses, con similitudes entre Mesoamérica, China, India y “quizás” Java, que preparó para el Congreso Internacional de Americanistas que se celebraría en México en agosto de 1962.

En otro congreso de especialistas posterior presentó un ensayo más detallado sobre el mismo tema. ${ }^{20}$ Sin embargo, su investigación comparativa sobre los sistemas religiosos entre Asia y Mesoamérica quedó inconclusa por su muerte, sucedida el 13 de septiembre de 1973.

Paul Kirchhoff fue, sin lugar a dudas, uno de los estudiosos americanistas (él mismo se definió como "mexi canista") cuya contribución al conocimiento de la historia prehispánica de México fue seminal.

No sólo porque provino de él la propuesta del concepto de una Mesoamérica cuyo estudio englobaba el conjunto de las culturas prehispánicas en México y América Central, ${ }^{21}$ sino también porque su trabajo de investigación y análisis de los documentos coloniales del siglo XVI en el valle tlaxcalteca-poblano fue invaluable (la nueva traducción y edición comentada de la Historia Tolteca-Chichimeca (1547-1560) se la debemos a él y a sus discipulos). ${ }^{22}$ Kirchhoff fue además un importante educador: una gran parte de la actual generación de antropólogos y 
arqueólogos -considerados hoy como los principales especialistas en la historia prehispánica de México- fueron sus discípulos.

Sin embargo, pocos de sus colegas, menos sus discípulos actuales, siguieron sus radicales propuestas difusionistas en la investigación mesoamericana: su paciente, por no decir obsesiva, clasificación de datos comparativos entre Mesoamérica y Asia con la cual él pretendió probar que partes esenciales del contexto cultural y religioso mesoamericano se importaron del Lejano Oriente a México, quedó inconclusa.

Kirchhoff sostuvo que existieron dos grandes momentos históricos de "importaciones culturales asiáticas" hacia Mesoamérica. La más antigua proveniente de China, y una segunda oleada, mil años después, desde regiones hinduizadas y budistas del sudeste de Asia. ${ }^{23}$ Opinó -por escrito, y también en voz alta en los congresos de especialistas e irritando el nacionalismo de sus colegas mexicanos- que sólo así era posible comprender la complejidad del alcance y sofisticación del calendario, la astronomía y las matemáticas en el horizonte clásico mesoamericano cuya base técnica y económica era muy rudimentaria.

¿Conoció Kirchhoff el torrente de especulaciones, mayormente de no académicos, que la traducción y argumentación de Neumann/ Leland desencadenó sobre el viaje del monje budista Hwui Shan a tierras americanas? ¿O conoció por sinólogos franceses y alemanes el relato del viaje de Hwui Shan en el siglo V?

Kirchhoff no alude con ninguna referencia directa a los viajes de Hwui Shan, pero sus conocimientos de los viajes de Von Humboldt eran precisos. "Por la ruta de China este sistema (religioso/calendárico) llegó a México" explicó agregando que las razones que él tenía para creerlo así eran que 
[...] en todo Asia sólo los chinos y los paises bajo su esfera de influencia conocian las especificidades del calendario mesoamericano que los españoles encontraron vigente en México y que recurría a una serie de doce dioses $y$ animales. ${ }^{24}$

Sus motivaciones para insistir en esta línea de investigación, explicó, eran que: "[...] Mesoamérica no debe ser un concepto limitado, como si en sus bordes terminara el mundo”. Además:

[...] porque Mesoamérica nunca fue un mundo cerrado sino simplemente una parte, nuestra parte, del mundo de los antiguos pueblos civilizados: ese mundo que abarcaba Egipto, Mesopotamia, la Gran India, China, México y Perú, para mencionar sólo los más importantes. Y ya en aquel tiempo la historia de nuestro país no fue una historia local sino que formaba parte de la historia universal. ${ }^{25}$

Kirchhoff apuntó también que Alexander Von Humboldt (quien el 5 de junio de 1799 se embarcó hacia las tierras americanas y retornó a Europa en 1804) había insistido en la semejanza que había entre México y las civilizaciones asiáticas, especialmente en relación con el calendario religioso:

[...] dos series de números o nombres, de desigual extensión -13 y 20 acá y 10 y 12 allá-que se combinan en cíclica repetición hasta que se hayan agotado las posibles combinaciones: 260 en México y 60 en Asia. Una de las dos listas es de animales (asi en Asia) o de animales más objetos y fenómenos no animales (asi en México), siendo varios animales iguales en ambas listas: serpiente, mono, perro y tigre; y el venado en la lista mexicana muy bien podría corresponder a la cabra en la lista asiática, con lo cual el número de semejanzas subiria a cinco. 
Kirchhoff apuntó también que Fritz Graebner -inspirado en Von Humboldt, un siglo después- había retomado el estudio comparativo de las cuentas calendáricas

[...] demostrando tres cosas decisivas: primero que en Siam la lista más corta consiste de numerales como en México y no de dos veces cinco elementos como en China, Japón y Tibet; segundo, que los cinco animales iguales se siguen en las dos listas en el mismo orden y con los mismos intervalos; y tercero, que en lo menos dos casos un objeto y un fenómeno no animado de la lista mexicana corresponde en la lista asiática a un animal doméstico que no se conocía en México, de modo que parece tratarse de una sustitución (muerte y caballo; caña y gallo).

"El suscrito", agregó Kirchhoff,

[...] ha podido agregar dos casos más... cuerda y rata, originalmente toro. Se ve ahora además que a una lista asiática de doce nombres se han agregado ocho más, en su mayoria objetos y fenómenos no animados, cuatro al principio y cuatro al final. Por eso, consiguientemente debemos comparar sólo los doce nombres centrales; $y$ de estos cuatro son iguales y cuatro sustitutos, siguiéndose unos $y$ otros en el mismo orden [...]. ${ }^{26}$

Para Kirchhoff la conclusión parecía ineludible:

[...] para el mexicanista que comprende el lugar clave que el calendario ocupa dentro de la estructura de la cultura mesoamericana; los resultados logrados por Humboldt y más aún por Graebner son una seria advertencia de una relación fundamental entre civilizaciones de Asia y América.

Y agregó: "Pero fueron bien pocos los que la supieron entender". 
Kirchhoff recordó así al "afamado" evolucionista "Tylor" (Sir Edgard Barnett Tylor) y citó su investigación sobre la similitud entre el juego de parchisi en la India y el juego de patolli del mexico del posclásico. ${ }^{27}$

Con esta referencia hizo una crítica velada al antropólogo más admirado del panteón de mexicanistas, Alfonso Caso, y su estudio del juego de patolli que no menciona, ni para refutar, a Tylor. ${ }^{28}$ Kirchhoff citó también los estudios de otro investigador austriaco, el doctor Robert Heine-Geldern, que investigó el arte de Amarávati en el sur de la India y sus semejanzas con el arte mesoamericano. ${ }^{29}$ Para Heine-Geldern este era un campo abierto a la investigación:

[...] tenemos pocas dudas acerca de que un análisis comparativo de la religión maya nos revelaria huellas de influencias tempranas hinduistas o budistas o ambas. Por sólo mencionar una, la concepción del infierno y del castigo que alli se imparte son similares a las creencias budistas e hinduistas a tal grado que asumir una relación histórica es casi inevitable. ${ }^{30}$

Kirchhoff apoyó esta propuesta con su propia investigación:

Recientemente el suscrito, continuando los estudios de Humboldt y Graebner, ha descubierto la transmisión a México desde alguna parte de la Gran India, quizás Java, de todo un sistema religioso: doce dioses que allá y acá se siguen en el mismo orden, con los mismos atributos y con semejantes predicciones de horóscopos [...].

Uno puede imaginarse la irritación -y el silencio que vendría- de los americanistas mexicanos ante estas propuestas de un alemán (de personalidad altanera y dificil, además) que con sus argumentos arrebata al nacionalismo mexicano, casi literalmente, ja los dioses de su pasado prehispánico! 


\section{EL POETA ${ }^{31}$}

Gary Beddes, de origen canadiense, decidió iniciar en el año 2000 un viaje siguiendo las huellas de Hwui Shan a la maravillosa tierra del Fusang.

Poco después de partir de Afganistán, lugar de nacimiento del monje budista, hacia China, ocurrieron los atentados a las torres gemelas de Nueva York. ${ }^{32}$

El poeta viajero canadiense, Gary Beddes, con su pasaporte estampado por el gobierno talibán, atravesó Pakistán y China y se embarcó hacia la tierra del Fusang, es decir, a México, con un pasaporte repleto de "pruebas" de que había visitado a los más temidos "enemigos de la libertad".

"Un viaje muy lejos", sin embargo, fue todo lo que le dijo un soñoliento soldado mexicano cuando revisó todos los visados de su travesía desde Asia mientras en una mano sostenía un fusil y con la otra le estampaba un sello en su pasaporte en Frontera Corozal, Chiapas.

El poeta se aprestaba entonces a cruzar el Usumacinta, la frontera acuática entre México y Guatemala.

El viaje, para entonces, se le antojaba al poeta más peligroso de lo que pudo haber sido para el monje budista miles de años atrás:

[...] mi caprichosa tarea de escribir un relato sobre un oscuro monje budista [...] aunada a mi confusión e inquietud [de estar en un escenario mundial post 9/11] me descubria de pronto viajando en medio de otro pestifero paisaje, sitio de carnicerías, y de un genocidio que inició con el arribo de los españoles y que no se ha detenido aún. 
Pero el poeta se hizo de valor y siguió las huellas de Hwui Shan y sus acompañantes, quienes permanecieron en la tierra del Fusang cuarenta años y cuya inquietud muy probablemente los llevó a migrar desde "Teotihuacan a los principales centros mayas que dominaron estos territorios entre 300 y 900 d.C." Visitó así museos y ciudades arqueológicas, también Tikal y Copán, hasta lograr una "[...] satisfacción personal de que el contacto precolombino con Asia no era pura quimera".

Dos poetas mexicanos, Homero Aridjis y Gabriel Zaid, se interesaron por él y le adelantaron sus propias sospechas de la relación entre Asia y Mesoamérica:

Hace varios años vi en el Museo de Mitla una pequeña pieza olmeca en posición de yoga que no podía ser una apariencia sino algo más real: urdhvapadmasana -la flor de loto invertida. Nadie tiene una explicación plausible [...]

le escribió Gabriel Zaid.

Homero Aridjis y su mujer Betty Ferder, neoyorquina con un doctorado en literatura medieval (además de traductora), por su parte, le enviaron copias de reportes periodisticos de unos recientes hallazgos hechos por Rubén Cabrera y Saburo Sugiyama en Teotihuacan; un entierro de tres personajes acomodados en la posición de loto; además de figuras en jade cuyas similitudes con esculturas budistas saltaban a la vista: los rostros tenían las mismas facciones apenas delineadas, narices anchas y labios gruesos que se conocen en esculturas orientales de la antigüedad.

Los reportes periodísticos y las opiniones de los arqueólogos, sin embargo, no referian similitudes ni influencia asiáticas y atribuyeron la posición en loto del entierro a una probable influencia maya. El poeta 
apuntó en su diario de viaje: "Aunque nadie hasta ahora puede explicar cómo pudo suceder eso".

La conversación entre el poeta canadiense y el poeta mexicano se tornó en un intercambio de sospechas compartidas: "Cuando vistamos Beijing y Shangal" le confió Aridjis

Yo le insistia a Betty "eso parece mexicano". Finalmente me pidió que me callara. Sucedió lo mismo en Japón, pero alli eran los rostros, los ojos, los pómulos, el grosor del labio inferior [...].

Pero cuando el poeta canadiense intentó un diálogo con un arqueólogo de Teotihuacan, se encontró con respuestas evasivas y descripciones, por decir lo menos, parcas. El registro ultra especializado de la información del arqueólogo de "una sequedad implacable"33 no incide, por suerte, ni en el ánimo ni en la imaginación del viajero que continuó tras las huellas de Hwui Shan. Juguetes del horizonte olmeca, con ruedas, en el museo de Jalapa; piezas femeninas con caderas voluptuosas y con "aire de sensualidad y abandono", esculturas mayas que tenían el aspecto y la forma de un Buda, pero sobre todo las réplicas de figuras de jade que pudo observar en La Venta, Tabasco, ${ }^{34}$ convencieron al poeta canadiense que él pisaba las huellas del monje Hwui Shan. Anotó entonces en su diario la siguiente observación:

El conjunto de quince figuras esculpidas en un jade pálido y prístino, con uno que parecía tallado de alguna piedra volcánica porosa de color rojo [...] expuestos dramáticamente, con la figura roja mirando a las otras. Detrás [...] implementos de jade para esculpir, las hachas, sobre los cuales estaban grabados diseños y marcas que parecian corresponder a una escritura primitiva. Este especial conjunto de figuras, sin significación religiosa o funeraria explicita, 
fue descubierto a tres pies de profundidad en La Venta y permanece como un enigma.

Mike Xu, un académico de la Universidad Católica de Texas, convencido de que estas hachas tenían inscripciones Shang, invitó a Han Ping Chen, un especialista en la escritura de la dinastía Shang, a Washington para examinarlas. ${ }^{35}$ Al académico chino le bastó unos minutos de observación de las inscripciones en las hachas de jade para pronunciarse: "Yo puedo leer esto. Claramente son caracteres chinos". Han Ping aseguró que el mensaje trasmitido estaba relacionado con algún evento especial, probablemente la fundación de una comunidad. Recurriendo a sus gastados diccionarios, Han identificó los caracteres de "líder" o "jefe" y otro carácter que se traducía en "fundar" o "establecer"; además reconoció otros símbolos pictóricos para "reino" o "país" en dos cimas de montañas triangulares subrayadas por una linea que representaba un río. ${ }^{36}$

El poeta canadiense explica así que la dinastía Shang reinó en tierras fronterizas con Huang He entre 1554 y 1045 a.C. Estas enigmáticas figuras olmecas en jade le indicaban, por eso mismo, que Mesoamérica recibió antiguas y prolongadas visitas desde Oriente. O por lo menos existía la duda o las pruebas a investigar.

Aunque nada de eso ocurrió. Sino más bien, según lo cuenta Beddes, lo que se sucedió fueron airadas acusaciones de "charlatanes" y muestras de indignación de parte de arqueólogos y académicos americanistas; alguno incluso llegó a insinuar que detrás de ello estaba la intención del gobierno de China de robarse el patrimonio cultural mesoamericano.

El poeta canadiense cuenta que Mike Xu se distanció de la traducción del chino Han Ping Chen quien aprovechando su visado en Estados 
Unidos simplemente se esfumó. Y así reinó nuevamente el silencio sobre la relación de Asia y México entre los investigadores del universo mesoamericano.

\section{¿Y?}

¿Hwui Shan arribó con cuatros monjes budistas a México en el siglo V? Esta pregunta, o mejor, esta posibilidad, continúa rondando y apasionando a muchos como el poeta Gary Beddes.

Aunque más exacto sería decir que lo que ronda y apasiona la imaginación de algunos es la posibilidad o probabilidad, como lo sustentó un historiador norteamericano en 1921, de que monjes budistas desde China llegaron a América a convertir a los mexicanos a sus creencias en tiempos de la antigüedad. "O Fusang arribó al continente americano, probablemente a México, o esta historia es una mentira" sentenció el doctor Charles Chapman. "Sin embargo la evidencia de que fue verdad pareciera abrumadora". 37

La historia de los congresos de americanistas en el siglo XX registra ciertamente sospechas insistentes de algunos estudiosos -como Miguel Covarrubias y Ángel M. Garibay- quienes buscaron comprobaciones de un contacto temprano entre Asia y Mesoamérica. ${ }^{38}$ Aunque entre los especialistas americanistas sólo existieron menciones incidentales de los viajes de ultramar de los monjes budistas a la tierra del Fusang citando a Von Humboldt o a los sinólogos de los siglos pasados.

Quizás no fue sólo la radicalidad de la posición difusionista -la idea de una importación/implantación de las culturas de Asia en Mesoamérica, que es además insostenible- la que lastimó cierto orgullo nacionalista de los antropólogos mexicanos e impidió profundizar mediante una investigación multidisciplinaria en la posibilidad de alguna interacción 
cultural asiática en Mesoamerica; sino el inicio y la tradición misma de las investigaciones sistemáticas y científicas de los americanistas sobre el desarrollo cultural mesoamericano: desde un inicio esta tradición insistió en demasía en "la autarquía de un continente separado de todos los demás mundos[...]",39 resguardado de la mirada europea, y que se desvaneció violentamente en el momento del contacto. Hasta que no hubo suficiente rescate arqueológico que hiciera que el tema del contacto exógeno en Mesoamérica fuera inevitable, la investigación de los americanistas estuvo relegada y renegada la documentación de los viajes e intercambios marítimos y terrestres que caracterizaron al comercio mesoamericano -hoy lo sabemos-desde sus primeras épocas (1200 a 500 a.C.).

La prehistoria de los orígenes, en principio, nos exhibe un continente americano que permaneció deshabitado por mucho tiempo hasta que pobladores humanos del género homo sapiens sapiens, de origen casi en su totalidad asiático, penetró al continente por el estrecho de Bering para conformar las culturas de los primeros cazadores-recolectores americanos entre 40,000 a 7000 a.C. Las características físicas del poblamiento inicial tuvieron muy probablemente contribuciones del Cáucaso y la India, pero el tipo físico dominante era mongoloide.

El arte y las manifestaciones culturales de Mesoamérica, es de sentido común suponerlos mucho más homogéneos en la primera época olmeca, ya que cuando representó figuraciones humanas mostró las características asiáticas reales de la población nativa mesoamericana. 


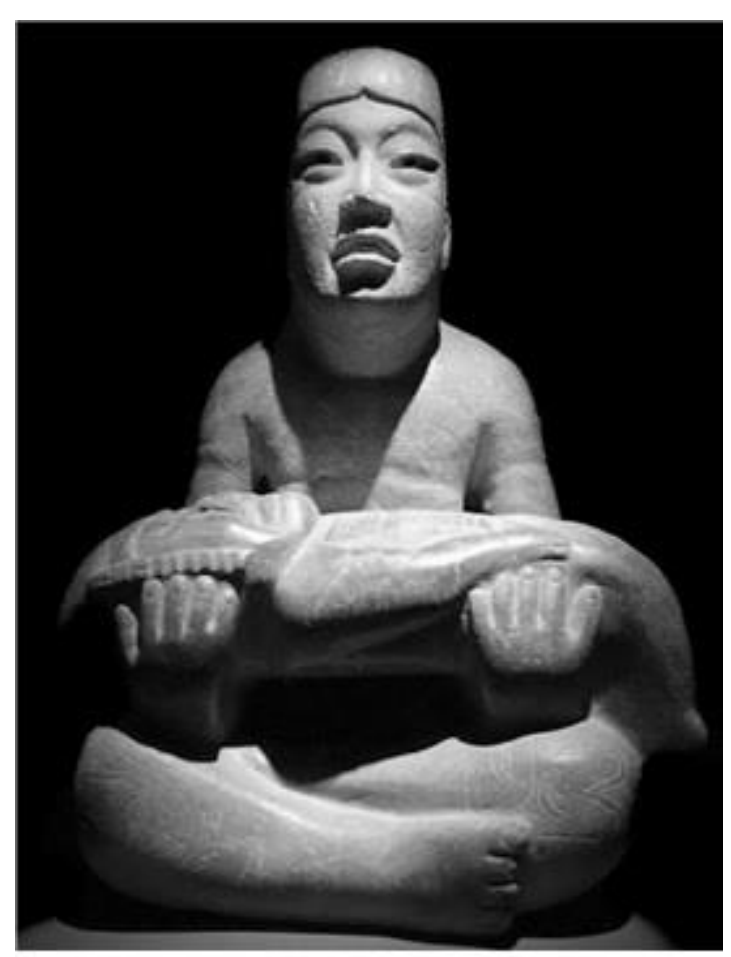

Figura 1. E1 Señor de las Limas.

Reconocer rasgos físicos asiáticos en las esculturas olmecas tempranas, por eso mismo, no debe sorprendernos. Ni pueden servir para probar o desmentir viajes marítimos de visitantes o inmigrantes que pudieron haber llegado por vía atlántica o del Pacífico, intencionalmente o por accidente, a Mesoamérica.

Lo que hoy sabemos por el rescate arqueológico es que Mesoamérica tiene, desde su primera época, relación e intercambio con culturas exteriores a su territorio vía terrestre y marítima, tanto por el Atlántico como por el Pacífico.

Cholula, la gran urbe comercial que rivalizó con Teotihuacan en su segunda y tercera época (200 a 800 d.C.) colonizó la costa del Pacífico de Honduras y Nicaragua y extendió sus redes comerciales y culturales hacia territorios chichimecas del norte de México; y más allá de las fronteras mesoamericanas, hacia el sur de Estados Unidos; tarascos o purépechas que ocupaban (y ocupan) el actual estado de Michoacán hablan un idioma de difícil clasificación según lingüistas 
contemporáneos: algunos han argumentado sus similitudes con el vasco, pero otros sostienen su parentesco con el quechua, la lengua de los incas peruanos así como el zuñi del sureste norteamericano.

¿Emigraron por una ruta marítima los purépechas a Mesoamérica desde el Perú? Hoy está documentado también el comercio marítimo que llegó a Mesoamérica por el Pacífico desde pueblos andinos así como por el Atlántico y el Caribe desde las islas caribeñas.

También las características del intercambio terrestre por la llamada frontera sur de Mesoamérica donde confluyen y se influyen con rasgos culturales provenientes de pueblos selváticos desde las cuencas del Orinoco y la Amazonia así como de los pueblos andinos.

Se han localizado estatuillas teotihuacanas en la isla La Tolita en Ecuador; en Nayarit se han excavado objetos de oro provenientes de Nazca, Perú, así como esculturas provenientes de la zona de Costa Rica y cerámica policromada del siglo IV y V también proveniente de Costa Rica; conocemos placas de cobre en Michoacán cuya procedencia se atribuye a las culturas andinas, y piezas de metalurgia relacionadas con el Ecuador.

Vasijas con asa de estribo y efigie del Valle de México, correspondientes a Tlatilco y fechadas entre 1000 a 800 a.C., algunas con formas antropomórficas o representando armadillos, peces, patos o tortugas, son estilos originados en Ecuador y Perú. Todo esto en un intercambio nortesur que fue más amplio y provechoso en Mesoamérica de lo que todavía nos cuesta aceptar.

¿Por qué no admitir así la posibilidad de un intercambio transatlántico o transpacífico a lo largo del desarrollo cultural propiamente mesoamericano? 
En Cassiar, British Columbia, se descubrieron monedas y un artefacto de bronce provenientes de China cuya antigüedad propuesta de 1200 a.C. provocó y provoca aún discusiones; existe cerámica atribuida a culturas chinas y japonesas en Valdivia y Machalilla, en Ecuador, fechadas alrededor de 200 a.C y la hipótesis es que navegantes asiáticos arribaron a Ecuador a finales del primer milenio antes de Cristo. ${ }^{40} \mathrm{El}$ arte de la navegación de los chinos es muy antiguo y se sabe hoy que ellos tuvieron conocimientos muy temprano de "las tierras al este del océano del Este". ${ }^{41}$ Para navegar los océanos fueron los primeros en recurrir al compás, ${ }^{42}$ por ejemplo, y lo hicieron con embarcaciones que podian acomodar hasta 300 pasajeros.

El doctor Robert Heine-Geldern y el arqueólogo norteamericano Gordon Ekholm, ${ }^{43}$ en 1951, en el Congreso de Americanistas en Chicago, sostuvieron que el contacto de Asia con el continente americano debió ocurrir en el primer milenio antes de Cristo desde la costa sur de China. Posteriormente arribaron navegantes de la cultura Dongson de Indonesia alrededor de los 400 a.C. y después.

Expusieron además que los contactos continuaron durante el primer milenio de nuestra era en dos periodos: del primero al sexto siglo y del noveno al siglo XII, hasta la disolución de los poderes políticos de la dinastía Khmer camboyana en 1219.

Sin suficientes investigaciones ni pruebas arqueológicas contundentes para sustentar este puntual itinerario, la hipótesis de Heine-Gelden y Eckholm persistió como hipótesis que nadie, tiempo después, ha retomado para desacreditar o sustentar.

Lo que ya fue imposible de sostener después de esta exposición, sin embargo, fue el recurrido argumento de que existía alguna imposibilidad 
de parte de los asiáticos para navegar largos tramos oceánicos hacia el continente americano en fechas tempranas y formativas de la cultura mesoamericana.

Apunto estos datos no para insistir en la hoy desfasada idea de que civilizaciones asiáticas -o externas- son el origen del arte, menos el calendario de la religiosidad y cultura mesoamericanas, sino para plantear más bien que no ha habido refutaciones válidas, o explicaciones plausibles, sobre paralelismos culturales entre algunas manifestaciones culturales mesoamericanas (incluyendo esculturas de la primera época que se inicia entre 1500-1200 a.C.) con Asia.

Y que, probablemente, si hubo desembarcos en el continente por la vía del Pacífico, seguramente fueron aislados y esporádicos, pero dejaron sus huellas quizás entre aquello que hoy resulta inclasificable o único en el sustrato cultural y demográfico compartido de Mesoamérica.

Apunto, por ejemplo, a las culturas de Occidente (Nayarit, Jalisco y Colima) donde las tumbas de tiro indican, quizás, una inmigración sudamericana costeando el Pacífico entre 600-500 a.C., pero donde también muchos de los rastros de su cultura antigua siguen siendo inclasificables en el contexto mesoamericano.

Entre las culturas de Occidente, por ejemplo, no se ha detectado ninguna presencia del arte teotihuacano. Allí reina más bien lo que los arqueólogos han descrito como un "espiritu de circularidad", en la organización del espacio y en las figuraciones y adornos de las esculturas prehispánicas. En Nayarit los arqueólogos le han puesto el nombre de "figurillas chinescas" a un estilo de abundantes figurillas con cabezas triangulares, cráneo superior alargado y de extraña figuración simétrica. 
Lo que inquieta al poeta debería inquietar también al antropólogo: el arte mesoamericano tiene algunas representaciones figurativas $\mathrm{y}$ simbólicas, zonas culturales enteras como la de los purépechas de Michoacán, que parecen no tener ascendencia ni descendencia, ni conexiones, ni explicaciones plausibles, en las otras tradiciones mesoamericanas. Y algunas son de fechas muy antiguas, como la que exhibe la misteriosa escultura del llamado Luchador de Uxpanapa, descubierta en 1933. O incluso el Señor de las Limas, de Veracruz, que ha recibido sin lograr consensos todo tipo de interpretaciones, y también perteneciente al horizonte olmeca.

La posición en cuclillas de muchas esculturas mesoamericanas tiene su antecedente y correspondencias en la figuración acostumbrada del jaguar, felino de simbolismo supremo en Mesoamérica, pero no así la posición que los mismos antropólogos describen como "flor de loto" en las magnificas figurillas de jade del entierro tres de la pirámide de la Luna en Teotihuacan (entre otras de la iconografia maya).

Finalmente, el viaje del monje budista Hwui Sha pareciera remover la sensación, o la intuición, de que aquí en Mesoamérica se han mezclado innumerables pueblos, y de que no son todos los que están ni están todos los que son. 


\section{N O T A S}

1- Agradezco la investigación que Margarita Ashwell realizó para la publicación de este ensayo. Ella fue la que me puso en la pista de Hwui Shan cuando me obsequió el libro de Gary Beddes, Kingdom of Ten Thousand Things, Sterling Publisher, March (2007).

2- Su nombre está occidentalizado -a lo largo de los siglos, en diversos documentos- y aparece indistintamente como Hoei-shin, Huisen, Hui-shen, Hoeishin, Fu Sang y Hwui-shin.

3- Samuel Wells Williams, profesor del Yale College presentó sus puntos de vista sobre este viaje ante la American Oriental Society el 25 de octubre de 1880 y anotó el nombre de la dinastía como Tsi. Véase de este autor "Notices of Fu-Sang and other Countries Lying East of China, Given in the Antiquarian Researches of Ma Twan-lin", Journal of the American Oriental Society, vol.11 (1882-1885) 89116, disponible en www.jstor.org/journal/aos.html

4- De Guignes escribe Li yen.

5- Nuevamente la grafia occidentalizada cambia según la fuente. S. Wells Williams escribe Wan Hien Tung Kao, anota los caracteres chinos y traduce al inglés este título como Antiquarian Researches. Lo he traducido al español como Investigaciones de antiguallas. Existe también la fecha de 1317 para la edición de la enciclopedia de Ma Twan Lin.

6- Tomado del libro y su amplia bibliografia de Gavin Menzies, 1421: The Year the Chinese Discovered America. Gavin Menzies comandó un submarino británico durante la Segunda Guerra Mundial; ya retirado escribió este libro. Su documentación y bibliografia son extensas, al igual que sus conocimientos sobre la navegación oceánica, pero sus investigaciones sobre el "descubrimiento" del continente americano por naves chinas en la antigüedad todavía aguardan validaciones y mayores comprobaciones.

7- “¿Por qué conservar esta absurda noción de 'clásico’?” se pregunta Christian Duverger. Toda la historia del México antiguo "va acompañada de cierta vaguedad cronológica" puntualiza en El primer mestizaje: La clave para entender 
el pasado mesoamericano, conacyt, inah, Taurus, México (2007). Seguiré, de ahora en adelante, su propuesta cronológica. Ver p.191.

8- El texto y las observaciones de Karl F. Neumann están incluidos en el libro de Charles G. Leland disponible en http://www.sacredtexts.com/earth/fu/index.htm El libro de Leland es del dominio público porque fue publicado en fecha anterior al 1 de enero de 1923. Existe también una nueva edición a la venta.El volumen de 800 páginas del norteamericano Edgard P. Vining llamado An Inglorious Columbus, editado en Nueva York en 1885 se encuentra digitalizado y disponible en http:// books.google.com/books?id=h29BAAAAIAAJ

9- Las uentes principales de la argumentación de que la tierra del Fusang estuvo en México en el libro de Leland son La historia de la conquista de México de Prescott -quien hoy sabemos nunca estuvo en México-, la Storia antica del Messico de Clavijero y Historia de le [sic] conquista de Bernal Dias [sic].

10- Wells Williams S. Op.cit.

11- "Chinese Whispers: Edward Payson Vining's Art of Error" de Ed Park, publicado en el Village Voice de Nueva York el 17 de enero de 2001.

12- Esta corriente en el Pacífico lleva por nombre, en otros documentos, Kuroshivo.

13- Wells Williams S. "Notices of Fu-Sang and other Countries Lying East of China, Given in the Antiquiarian Researches of Ma Twan-lin", Journal of the American Oriental Society, vol.11 (1882-1885).

14- Ver, por ejemplo, "Was America the Wonderful Land of Fusang?" de Robert Larson, American Heritage Magazine, abril (1966). Larson es artista y periodista. Cabe recordar también la aventura en barca (y publicaciones relacionadas con ella) de Thor Heyerdahl en el Kon-Tiki y su travesía por el Pacífico en 1962; o la de Kenichi Oiré en su bote de vela; si bien estas travesías fueron por el Pacífico Sur desde Polinesia hacia el Perú. Ésta es una ruta, según explican algunos expertos en viajes maritimos, posiblemente más difícil que la que pudieron haber usado los monjes budistas por el Pacífico Norte para arribar al continente americano. 
15- Wells Williams S. "Notices of Fu-Sang and other Countries Lying East of China, Given in the Antiquiarian Researches of Ma Twan-lin", Journal of the American Oriental Society, vol.11 (1882-1885) 89-116, está disponible en esta dirección: www.jstor.org/journal/aos.html En esta contribución de Wells se incluye todo el relato, traducido al inglés por Leland, del viaje de Hwui Shan.

16- Existe otra grafia occidentalizada para estos nombres ofrecidos por Neumann/Leland: Tuilu, pequeño Tuilu y Na-to-scha.

17- "Five pecks" o "five bushels" es la cantidad traducida al inglés por Charles G. Leland.

18- Tomado de la traducción de Neumann/Leland (1875) y de S. Wells Williams (1880).

19- Fólder 506, Caja A-11, Archivo Kirchhoff, Biblioteca del inah Puebla. El ensayo no está fechado, pero tiene la referencia del Congreso de Americanistas que se celebraria en "agosto".

20- De Paul Kirchhoff, "The Adaptation of Foreign Religious Influences in PreSpanish Mexico", Diógenes (1964). Sólo existe una versión en inglés que se puede consultar en http://dio.sagepub.com

21- Kirchhoff P. "Mesoamérica: sus límites geográficos, composición étnica y caracteres culturales", Acta Americana, vol. I, 92-107.

22- A instancias de Guillermo Bonfil Batalla, director del inah, el trabajo de terminar la edición, revisión y traducción de los documentos coloniales conocidos como la Historia Tolteca-Chichimeca quedó bajo la dirección y conclusión de Luis Reyes y Lina Odena Güemes.

23- Ver a Carlos García Mora en Paul Kirchhoff: Escritos selectos, vol. I, unam (2002).

24- "The Adaptation of Foreign Religious Influences in Pre-Spanish Mexico", op. cit.

25- "México entre Oriente y Occidente", op. cit.

26- A partir del estudio, la publicación y traducción de los códices prehispánicos y coloniales -especialmente el Códice Borgia que contiene el tonalpohualli o 
calendario sagrado y adivinatorio- la medición del tiempo y el espacio mesoamericano son finalmente accesibles. También su complejidad: son cuentas sagradas, espaciales y temporales a la vez. Kirchhoff hace referencia a este calendario -el tonalpohualli- de 260 dias, ordenado en 20 trecenas, en el cual cada signo del calendario está asociado a una dirección del universo según un movimiento de rotación inmutable: Este, Norte, Oeste, Sur. El primer signo, cipactli/imix, está asignado al Este; el segundo, ehecatl/ik, al Norte; el tercero, al Oeste; el cuarto, al Sur y el quinto, al Este, y así sucesivamente. Una fecha siempre está vinculada con una dirección del universo. Los signos del Este son el cocodrilo, la serpiente, el agua, la caña y el movimiento. Los signos del Norte son el viento, la muerte, el perro, el jaguar y el pedernal. Los signos del Oeste son la casa, el venado, el mono, el águila y la lluvia. Los signos del Sur son el conejo, la lagartija, la hierba, el zopilote y la flor. Kirchhoff apuntala las similitudes que existen entre estos símbolos mesoamericanos con los símbolos calendáricos asiáticos. Ver: Anders F, Jansen M, Reyes García L, Los Templos del Cielo y de la Oscuridad, libro explicativo del llamado Códice Borgia, fce, México (1993).

27- Tylor EB. "On the game of Patolli in Ancient Mexico and its probable Asiatic Origin", Journal of the Royal Anthropological Institute of Great Britain and Ireland, vol. 8 (1879).

28- En la ponencia publicada (Diógenes: 1964) Kirchhoff sólo menciona, sin ninguna referencia a Caso, el estudio de Tylor. Alfonso Caso respondió a las propuestas difusionistas de Kirchhoff en “Answer to Paul Kirchhoff” en Diógenes, no. 47 en 1964. Pesos pesados de la antropología americanista, como Martínez del Río, pero también Kroeber AL, Taylor HC y Fraser D apoyaron a Alfonso Caso en esta controversia. Alfonso Caso desacreditó la postura de Kirchhoff recurriendo a los tiempos de los horizontes arqueológicos mesoamericanos que no corresponden, según sostuvo, con la aparición de los calendarios en Asia y menos con la posibilidad de viajes transpacíficos porque el calendario mesoamericano hace su aparición en el horizonte olmeca en el primer milenio antes de Cristo.

29- Heine-Geldern murió en 1967. Dedicó su vida al estudio de las similitudes simbólicas e iconográficas entre las culturas hindúes con México y América Central. Una bibliografia parcial de su obra se encuentra en Gardini W, “Asiatic Influences on 
Pre-Columbian Cultures", Diógenes (1974); 22; 106. Disponible en http://dio.sagepub.com ; publicado por sage Publications www.sagepublications.com

30- Von Heine-Geldern R. Significant Parallels in the Symbolic Arts of Southern Asia and Middle America (1951). Ver también "Cultural Connections between Asia and Pre-Columbian America" en Anthropos, vol. 45, (1950) y "The Problem of Transpacific Influences in Mesoamerica" en el Handbook of Middle American Indians, vol. iv, Austin (1966).

31- Beddes G. Kingdom of Ten Thousand Things, Sterling Publisher, March (2007).

32- 11 de septiembre de 2001.

33- He tomado prestada esta frase de Christian Duverger. Ver El primer mestizaje: la clave para entender el pasado mesoamericano, conacyt; inah, Taurus, México (2007) 15-16.

34- Se refiere a la Ofrenda 4 de La Venta, Tabasco. Horizonte olmeca. Son en realidad 16 figuras de jade asociadas a seis hachas. Las figuras están colocadas de pie, sobre un piso de arena, y las hachas están clavadas también en la arena como si fueran estelas. Actualmente este conjunto de figuras está bajo el resguardo del Museo Nacional de Antropologia; son consideradas por los especialistas entre las piezas más misteriosas y notables del horizonte cultural olmeca mesoamericano. Coincidentemente adornan la tapa de la edición del libro citado de Christian Duverger.

35- Esta y otras piezas fueron expuestas en la Galería Nacional de Arte de Washington dc en 1966.

36- Mike Xu ofreció posteriormente esta lectura completa de las hachas: "Practiquemos la adivinación sobre el entierro en el templo de piedras y hagamos ofrendas de sacrificio para conocer el espiritu de los ancestros". Es importante considerar que el lenguaje escrito típicamente mesoamericano es simbólico, como lo explica Duverger C (op. cit.). Más aún, los olmecas, originarios inventores de la escritura mesoamericana combinan una búsqueda estética en sus glifos y representaciones figurativas. Los glifos son ideográficos y no tienen conexión lógica 
con alguna fonetización. La escritura ideográfica -no sólo la olmeca- se puede así fonetizar en cualquier idioma.

37- Chapman CE. "The Chinese along the Pacific Coast in Ancient Times" en A History of California: The Spanish Period, New York (1921).

38- Heine-Geldern había formado discípulos e investigadores que siguieron sus teorias. Después del XXIII Congreso de Americanistas y la influencia de Kroeber AL estas lineas de investigaciones fueron desdeñadas como provenientes de "entusiastas bien intencionados", pero sin validez científica. Estudiosos y apasionados del arte mesoamericano mantuvieron, sin embargo, la investigación sobre la relación entre Asia y Mesoamérica. Ver, Covarrubias M, The Eagle, the Jaguar and the Serpent. Indian Art of the Americas, New York (1954). Garibay AM, "Semejanzas de algunos conceptos filosóficos de las culturas hindú y nahuátl" en Cuadernos Americanos, México, vol.103 (1959). Naudou J también dejó inconcluso, por su muerte, un estudio comparativo entre el estilo de los frisos Amarávati y el Templo de los Jaguares en Chichén Itza: “A propos d'un éventuel emprunt de l'art maya aux arts de l'Inde extérieure" en Actas del XXXIV del Congreso Internacional de Americanistas, Viena (1962).

39- Duverger C. Op. cit.

40- Megger B, Evans C, Estrada E. Early Formative Period of Coastal Ecuador. The Valdivia and Machalilla Phases, Smithsonian Institute, Washington (1965).

41- Un poema chino del siglo III dice: "al este del Océano del Este están / las costas de la tierras del Fusang / si al arribar alli viajas / hacia el Este por 10 mil li / 1legarás a otro océano azul/ vasto, enorme, sin fin”. Citado por Robert Larson en su artículo para la revista American Heritage de abril (1966). Op. cit. Zu Qian-zhi en su ensayo titulado "Fu-sang-gwo Kao-sheng" de 1941, según nos explica Gardini W, op.cit, refiere que Fusang es un término que se usaba en China para el Japón con anterioridad al viaje de Hwui Shan en el siglo V.

42- El compás magnético hizo su aparición durante la dinastía Qin (221-206 a.C.). Con mucha anterioridad los adivinadores de la fortuna en China utilizaron un mineral de óxido de hierro que se alineaba en dirección Norte-Sur. 
43- Gordon Ekholm es el primer arqueólogo que investiga sistemáticamente las secuencias culturales mesoamericanas de Sonora y Sinaloa.

\section{Agradecimientos:}

A la Revista Elementos

Elementos es una revista trimestral de ciencia y cultura, de la Universidad Autónoma de Puebla, México. 